\title{
Effect of material elastic properties and surface roughness on grip performances of ski boot soles under wet and icy conditions
}

\author{
Matteo Moncalero ${ }^{\mathrm{a}}$, Stefano Signetti ${ }^{\mathrm{b}}$, Barbara Mazzantic ${ }^{\mathrm{c}}$, Pietro Bruzzi ${ }^{\mathrm{c}}$, \\ Nicola M. Pugno ${ }^{\mathrm{b}, \mathrm{d}, \mathrm{e}, *}$, Martino Colonna ${ }^{\mathrm{a}, * *}$ \\ ${ }^{a}$ Department of Civil, Chemistry, Environmental and Materials Engineering, \\ University of Bologna, via Terracini 28, I-40122 Bologna, Italy. \\ ${ }^{b}$ Laboratory of Bio-Inspired and Graphene Nanomechanics, \\ Department of Civil, Environmental and Mechanical Engineering, University of Trento, \\ via Mesiano 77, I-38123 Trento, Italy \\ ${ }^{c}$ Centro Ceramico Bologna, via Martelli 26, I-40122 Bologna, Italy \\ ${ }^{d}$ School of Engineering and Materials Science, Queen Mary University of London, \\ Mile End Road, E1 4NS London, UK \\ ${ }^{e}$ Ket-Lab, Italian Space Agency, via del Politecnico snc, I-00133 Roma, Italy
}

\begin{abstract}
A set of thermoplastic materials employed in soles for alpine skiing boots were characterized in terms of chemical composition, cristallinity, hardness, surface roughness, and grip. The results of friction experiments on different substrates reproducing the real environmental scenarios point out that materials provide more grip as they become softer. Moreover, higher roughness results in lower dynamic coefficient of friction (COF). Finite element simulations corroborate the experimental measures of $\mathrm{COF}$ and let to rationalize the role of material elasticity and surface roughness on the frictional characteristics of soles. The measure of grip on an inclined wet surface provides analogous results, indicating that COF can be used as key performance indicator in the design of ski-boot soles and of other anti-slip equipments in wet and icy environments.
\end{abstract}

\footnotetext{
${ }^{*}$ Corresponding author at University of Trento

** Corresponding author at University of Bologna

Email addresses: nicola.pugno@unitn.it (Nicola M. Pugno), martino.colonna@unibo.it (Martino Colonna)
} 


\section{Introduction}

Slips and falls are very common when walking on ice (Fleischer et al. (2014)) and they can be the cause of injuries of skiers in both outdoor environment (e.g., on ski slopes and resort walking areas) and indoor. For example, it is reported by Fleischer et al. (2014) that in Alaska approximately $10 \%$ of the injuries related to falling-through-the-ice (FTI) are connected to sport activities such as skiing and other adventure sports. For this reason, it is of crucial importance to identify the factors that influence the grip of the materials used for the production of soles on wet and icy surfaces (Tsai \& Powers (2013)). The soles of alpine ski boots are generally made of the same hard materials (polyolefines- or polyurethane-based thermoplastic polymers) used for the main body of the boot, ranging from 50 to 65 Shore D hardness (Colonna et al. (2013, 2014); Nicotra et al. (2015)), and have a limited tread which result in a limited friction with slippery surfaces (Grönqvist \& Hirvonen (1995)). This type of construction aims at reducing the costs and complexity of the moulds used for the production (Colonna et al. (2014)). Nevertheless, in recent years several manufacturers have started to produce boots with interchangeable soles (Colonna et al. (2013)) made of softer materials with respect to the plastics used for the body, in order to improve their antislip properties. On the other hand, the soles for ski-touring and freeride skiing boots are made of thermoplastic elastomers or vulcanized (natural or synthetic) rubber, to provide good grip when hiking and climbing.

The sole of a ski boot must have a stiff behaviour in order to efficiently transmit the impulse from the boot to the ski but, at the same time, a good grip on icy and wet surfaces. Generally, stiffer materials have lower friction resistance on hard and wet surfaces compared to soft materials (Gao et al. (2003)). The drawback of using soft rubbers is the lack in power transfer between the skier and the ski due to sole excessive bending under load, leading to a less precise control of the skis. Moreover, the efficient and safe behaviour of the binding in releasing the boot during a fall is strongly influenced by the geometry and the hardness of the parts in contact. In recent years some producers have provided the possibility to change the heel and the toe of the sole in order to have boots with desired properties according to the specific application. This type of sole is generally attached to the shell using metal screws. Therefore, alpine ski boots must be realized observing limits and prescriptions in terms of dimensions, materials and design of the boot interface. Two ISO standards (5355 and 9523, ISO $(2005,2008)$ ) rule the design of ski 
boots (Colonna et al. (2013)), defining the area of the ski boot in contact with the binding. In terms of materials used, both standards require that the hardness of the material at the toe and heel binding interface must be not less than 50 Shore D, measured at a temperature of $+23^{\circ} \mathrm{C}$ in accordance with ISO 868 (ISO (2003)). ISO 5355 specifies that the dynamic friction coefficient between the boot material and a low friction element of PTFE must be less than 0.1. Only when materials different from thermoplastic polyurethane (TPU) are used in the heel part of the boot, there must be at least one longitudinal low friction area to act as a bearing surface for the ski-brake. ISO 9523 requires a minimum percentage of the area in contact with the bearing surface of the binding of $25 \%$ in the toe and of $40 \%$ in the heel but no restriction in the characteristics of the material for the sole are prescribed. Ski-boots producers are currently pushing for the development of new standards that take into account different types of bindings. Since the amount of ski-mountaineering boots produced is less than $5 \%$ of the overall ski boots market (Colonna et al. (2013); Nicotra et al. (2015)) the interest of ski boot manufacturers and of researchers is mainly focused toward the study of soles for alpine skiing.

In recent years a significant work was performed in order to understand and model the friction behaviour of elastomers, mainly due to the interest of the automotive industry on this topic. For example, Heinrich \& Klüppel (2008) have investigated the role of rubber friction on tire traction, focusing on the load and velocity dependence of the friction coefficient. Attention has also been given to the study of materials used for the sole of shoes. Especially, Derler et al. (2008) have studied the influence of abrasion and temperature on grip, combining measurements of friction and hardness. Li et al. (2006) have investigated the correlation between the tread groove depth and the coefficient of friction on different wet and water-detergent covered floors, finding to be not significant in those conditions.

Some authors have focused their attention on soles friction on ice. For instance, Grönqvist \& Hirvonen (1995) have tested 49 types of winter footwear on dry and wet ice. From their evaluation, material type and hardness, as well as cleat design, were the most important factors on dry ice. On the other hand, only on wet ice the tread design had an influence on the friction properties. The high slipperiness of melted or wet ice was confirmed by Gao et al. (2003) who measured the effect of sole abrasive wear on the coefficient of friction on dry and melting ice. The results proved that artificially induced abrasive wear of soles increased slip resistance on hard ice, but not on melting ice. In 
the end, the chemical composition and the hardness (the latter dependent from the first) have an effect also on the scratch resistance that may affect the surface roughness in the long term (Budinski (1997)). Thus, it is clear the need of a study that takes into account different material parameters (namely chemical composition, hardness, and surface roughness) in order to obtain the best balance in terms of energy transfer and of grip on wet and icy surfaces.

The exploitation of numerical simulations in the realization of sports equipment is widely acknowledged by the industries and it represents an unavoidable step for the design of optimized and high performance products, limiting the cost of physical experimentation and prototyping to few calibration and verification tests. Regarding ski boots a number of work has focused on the structural design and optimization (Corazza \& Cobelli (2005); Natali et al. (2014); Parisotto et al. (2012)). However, to the best of authors' knowledge, no specific application of computational tools was use in the study and design of the grip performances of soles.

The aim of this work was to evaluate the friction performance of different materials used in ski boot soles on wet floors and icy conditions, correlating the performances with the chemical composition of the material, with its elasticity (hardness) and with the sole surface roughness. Finite Element Method (FEM) numerical simulations were used to fit the experimental results in order to understand general trends and extend the investigation domain.

\section{Materials and methods}

\subsection{Materials characterization}

A total of six different mould injected soles were tested: soles 1 and 2 are biinjected with a geometry (design 1) shown in Figure 1(a) while soles from 3 to 6 are mono-injected with a geometry (design 2) shown in Figure 1(b). Materials for sole groups 1-4 and 5-6 were provided by two different manufacturers. All the soles are conform to the ISO 5355 standard.

The chemical composition of all the soles was determined via Fourier Transform Infrared Spectroscopy (FT-IR) using a Perkin Elmer Spectrum One spectrometer equipped with an Attenuated Total Reflectance (ATR) detector. The Shore D hardness of the materials was measured according to the ISO 878 standard at $+23{ }^{\circ} \mathrm{C}$ and at $-10^{\circ} \mathrm{C}$ in order to evaluate the temperature dependence of hardness. Calorimetric measurements were carried out in order to measure the crystallinity and melting temperature of the materials, using a Perkin Elmer DSC6 differential scanning calorimeter (DSC) equipped with 

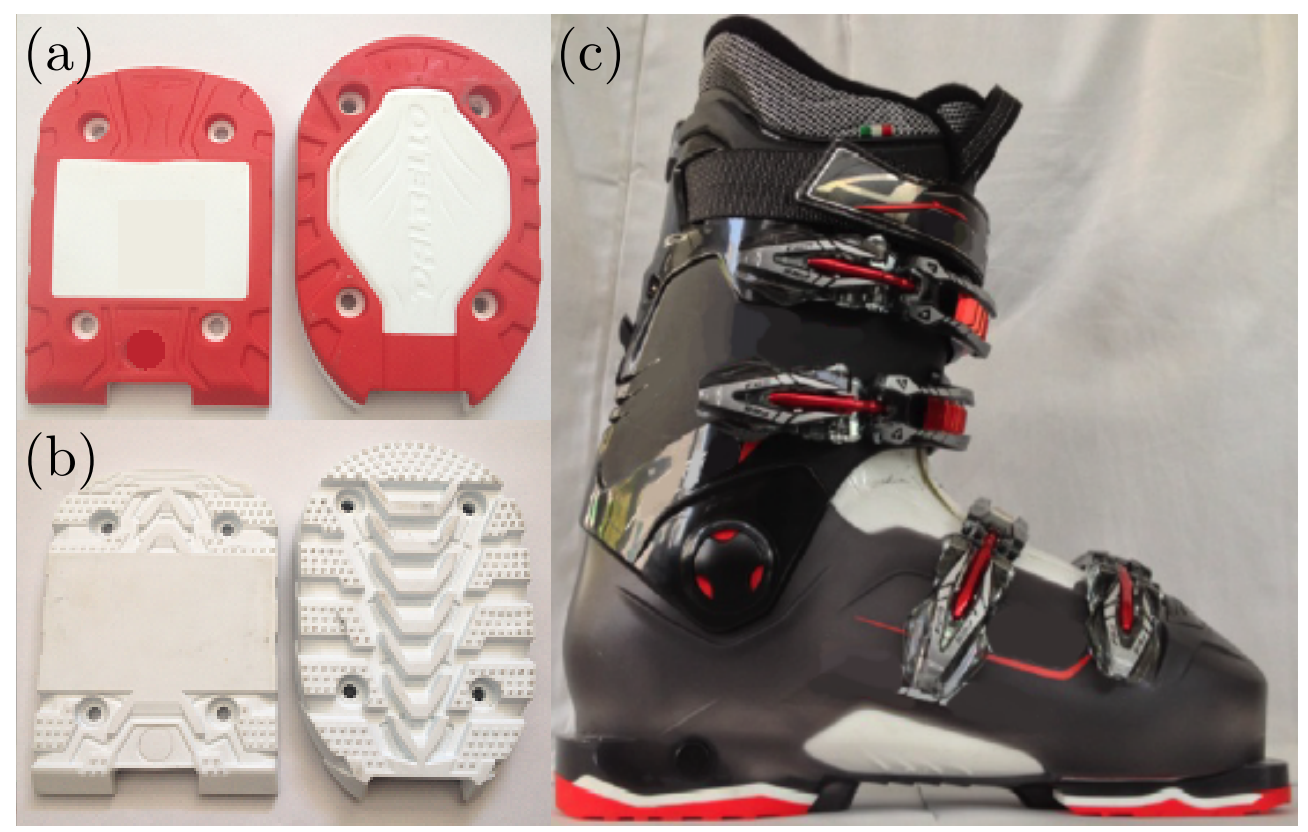

(b)

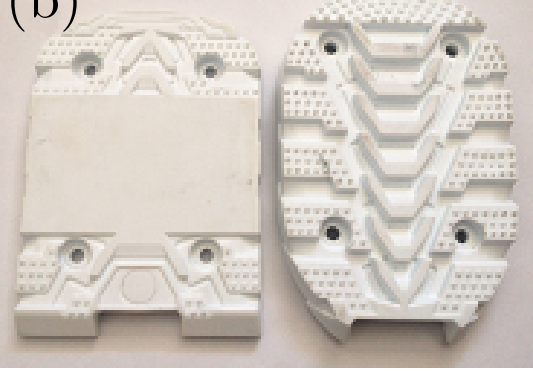

Figure 1: Samples of (a) design 1 sole and (b) design 2 sole and (c) ski boot used for the evaluation of the grip performance of the soles in the ramp test.

a liquid sub-ambient accessory and calibrated with high purity standards. Weighted samples of approximately $10 \mathrm{mg}$ were encapsulated in Aluminum pans and heated up to $250^{\circ} \mathrm{C}$ at a rate of $20^{\circ} \mathrm{C} / \mathrm{min}$.

\subsection{Surfaces characterization}

The contact area between the boot sole and the ground was measured with an image analysis technique, usually used in biological sciences, performed on a PMMA transparent platform (see Supplementary Figure 1(a)). The image analysis and processing was done using an open source software (Image $J$ ) which, through its threshold colour plugin, allows the selection and isolation of specific colours or grey-scale tones and its area measurement (see Supplementary Figure 2). In order to have a good contrast between the areas in contact with the Plexiglass@ surface and those not in contact, a solution of water and black wall paint (with a concentration of $1.3 \mathrm{~g} / \mathrm{L}$ ) was used (see Supplementary Figures 1(b) and 2). A total of 5 measurements for each sole were preformed and the final area determined as the average.

The sample surface texture characteristics were evaluated using an optical profilometer LEICA DCM 3D (Leica Microsystems), using a confocal objective 
with 20x magnification. The areal surface roughness parameters, in particular the arithmetic average height of the surface $S_{\mathrm{a}}$ and the root mean square gradient $S_{\mathrm{dq}}$, were measured according to ISO 25178 (ISO (2012)) over a sampling length of $900 \mu \mathrm{m}$. The acquired areas were also processed through binarization, setting a threshold value of $12 \mu \mathrm{m}$ for the distinction of the grains.

\subsection{Friction and grip experiments}

Friction tests were performed over three different surfaces, considered as the most representative for the ski boot field of use. Porcelain stoneware and float glass were tested in the laboratory $\left(+20^{\circ} \mathrm{C}, 60 \% \mathrm{RH}\right)$ while the test on ice was performed on a indoor ice skating field $\left(-10^{\circ} \mathrm{C}, 70 \% \mathrm{RH}\right)$. The porcelain tiles were used to simulate a ceramic flooring of alpine huts, while wet glass was used in order to test an alternative surface to mimic the behaviour of iced surfaces. The dynamic coefficient of friction was obtained in accordance with the British Ceramic Research Association (B.C.R.A.) method, that measures the resistance of ceramic tiles to slipperiness through a patented device. This device (for this study Scivolosimetro SM, Gabbrielli Technology S.r.l., Italy) belongs to the category of the "drag-sled meters": it travels across the flooring under its own power at a constant speed with a sample of standardized dimensions dragging on the surface. The machine directly computes an average dynamic friction coefficient from records along the travel of a predetermined path length. The main advantages of this technique are the ease of use and capability to run many tests in a short time in different conditions. Furthermore there is negligible influence of the operator on the results of the test since it is completely automated. For this work, each sole was tested six times in each condition calculating mean value and standard deviation for each configuration.

The grip of soles on wet surfaces was then measured using a standard procedure for testing the slipperiness of different surfaces according to DIN 51130-R ramp test (DIN (2004)). A ski boot in size $25.6 \mathrm{~cm}$ with changeable soles (Figure 1(c)) was used for the test. The tests were performed at $+20{ }^{\circ} \mathrm{C}$, in wet condition, using porcelain stoneware as surface. In this method, a tester stands on a ramp while its angle is constantly increased until the operator slips at a limit configuration. A total of five tests for each sole were performed, using three different human testers. 


\subsection{Finite element simulations}

3D finite element sliding simulations were performed in order to evaluate the role of the material elasticity and of surface roughness on the dynamic friction coefficient of soles on different substrates. The model is constituted by a deformable slider moving on a rigid surface. The deformable slider has dimensions of $1 \times 1 \times 0.5 \mathrm{~mm}^{3}$ and the motion is imposed via a constant velocity $v=0.01 \mathrm{~m} / \mathrm{s}$ on a backing rigid rod after being relaxed under the application of a normal distributed preload of resultant $F_{\mathrm{N}}$. The sliding scheme is analogous to the one adopted by Otsuki \& Matsukawa (2013).

A linear elastic isotropic constitutive relationship was used to model the TPU material. To estimate the Young's Modulus of the TPU from the measured hardness, the following empirical exponential relationship proposed by Qi et al. (2003) was adopted:

$$
\log E=(S D+50) \cdot 0.0235-0.6403
$$

which correlates the Shore D hardness to the material elastic modulus expressed in MPa. The Poisson's ratio was set $\nu=0.48$ as reported by Qi \& Boyce (2005), for all specimens independently from the sole.

Surface roughness was modelled with an equivalent sinusoidal function in the form $z=A \sin (\lambda x) \cos (\lambda y)$ where the amplitude $A$ was assumed to be equal to $S_{\mathrm{a}}$ while the parameter $\lambda$ was determined in order to obtain a sinusoidal profile with the same experimentally measured surface root mean square gradient $S_{\mathrm{dq}}$. The law used in the contact model to compute the local dynamic friction coefficient as a function sliding velocity $v$ at the contact interface, assumes the expression $\mu=\mu_{\mathrm{D}}+\left(\mu_{0}-\mu_{\infty}\right) e^{-v / v_{\text {crit }}}$ function of the relative velocity $v$ of the sliding node with respect to the reference surface, where $v_{\text {crit }}$ was assumed here to be equal to $0.001 \mathrm{~m} / \mathrm{s} . \mu_{0}$ and $\mu_{\infty}$ were taken as calibration parameters including the contribution of substrate elasticity and roughness, not experimentally determined, and of lubrication induced by wet conditions. The macroscopic dynamic coefficient of friction (COF) is determined as the slope in the tangential force at the contact interface vs. the applied normal load $\left(\frac{\mathrm{d} F_{\mathrm{T}}}{\mathrm{d} F_{\mathrm{N}}}\right)$, being the normal applied pressure in the range $0.01 \mathrm{MPa}-0.10 \mathrm{MPa}$ with steps of $0.01 \mathrm{MPa}$. 


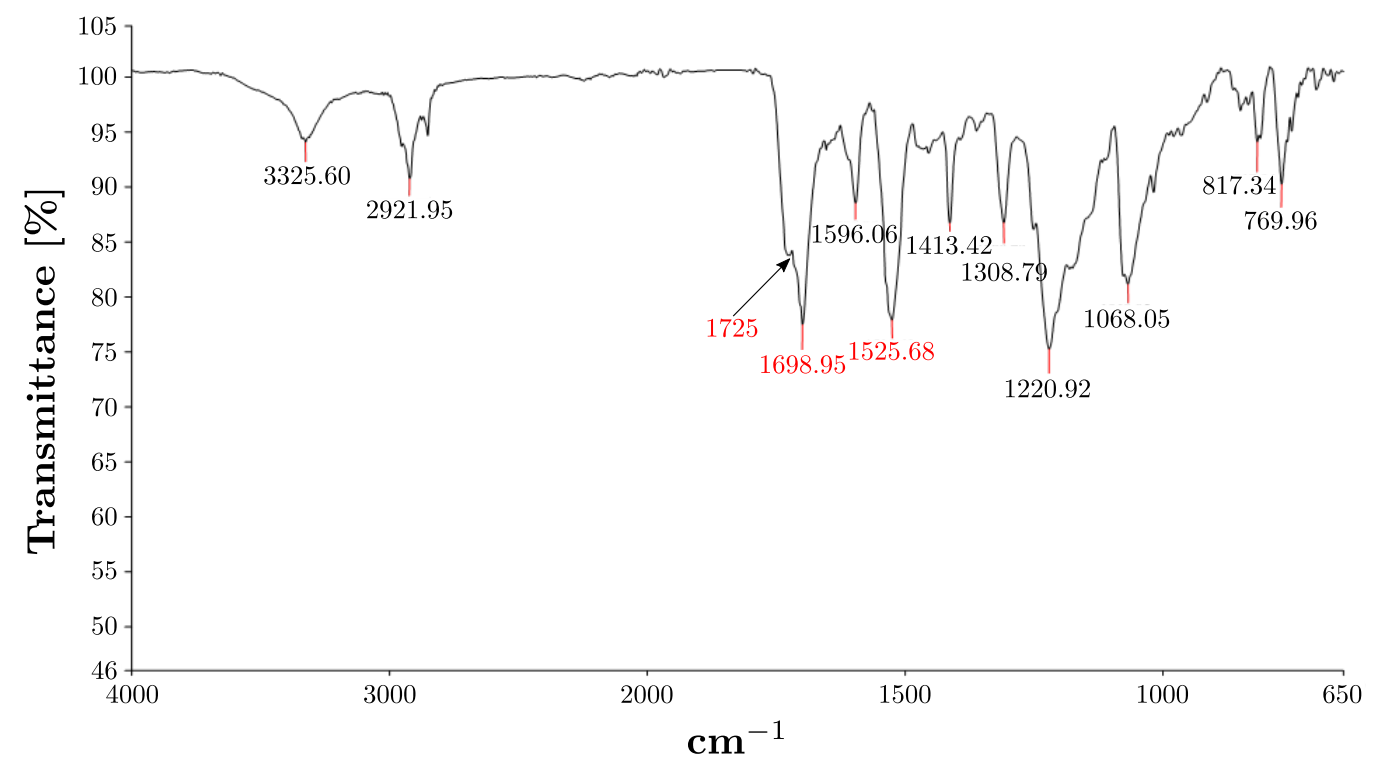

Figure 2: FT-IR spectrum of sole 1 with the characteristic points highlighted.

\section{Results}

\subsection{Chemical and mechanical characterization of materials}

The resulting FT-IR spectra were compared to a database of known polymeric materials. The analysis (Figure 2) shows that the soles are made of thermoplastic polyurethanes due to the presence of a peak at $1699 \mathrm{~cm}^{-1}$, of a shoulder at $1725 \mathrm{~cm}^{-1}$ and of a peak at $1525 \mathrm{~cm}^{-1}$ (Colonna et al. (2013)). The polyurethanes that compose the soles are based on methylene diphenyl diisocyanate (MDI) due to the presence in FT-IR spectra of a peak at $1596 \mathrm{~cm}^{-1}$ (Colonna et al. (2013)). All materials tested show the same FT-IR pattern and therefore a similar chemical composition.

We then measured the melting temperature and crystallinity of all samples by DSC (Figure 3 and Table 1). The materials are all semi-crystalline with a larger melting peak at around $180-210^{\circ} \mathrm{C}$ and a smaller melting transition around $50-100^{\circ} \mathrm{C}$. The melting temperatures $\left(T_{\mathrm{m}}\right)$ and heat of fusion $\left(\Delta H_{\mathrm{m}}\right)$ at the main melting peak are reported in Table 1. DSC, hardness and FT-IR analyses have shown that the two parts with different colours present on both soles 1 and 2 (Figure 1) are all made of the same material. Materials used for soles 2 and 3 are identical and the two differ only for the type of design. Materials used for soles groups 1-4 and 5-6 differs in the degree of crystallinity 

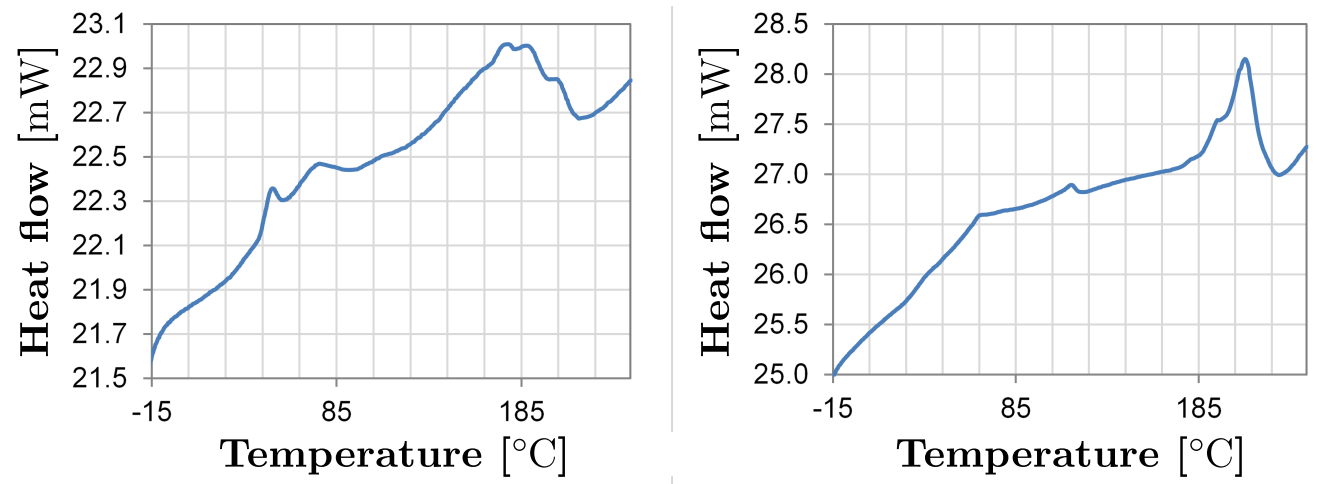

Figure 3: DSC heating curve of the materials of sole 1 (left) and sole 5 (right).

Table 1: Thermal properties (melting temperature $T_{\mathrm{m}}$ and heat of fusion $\Delta H_{\mathrm{m}}$ ), Shore $\mathrm{D}$ hardness at two different testing temperatures, its variation with decreasing temperature, and roughness measurements (average $S_{\mathrm{a}}$ and root mean square gradient $S_{\mathrm{dq}}$ ) through profilometer, for the different materials and surfaces of the tested soles.

\begin{tabular}{cccccccc}
\hline sole & $\begin{array}{c}T_{\mathbf{m}} \\
{\left[{ }^{\circ} \mathrm{C}\right]}\end{array}$ & $\begin{array}{c}\Delta H_{\mathbf{m}} \\
{[\mathrm{J} / \mathrm{g}]}\end{array}$ & $\begin{array}{c}\text { Shore D } \\
\left(+23^{\circ} \mathrm{C}\right)\end{array}$ & $\begin{array}{c}\text { Shore D } \\
\left(-10^{\circ} \mathrm{C}\right)\end{array}$ & $\begin{array}{c}\text { Shore D } \\
\text { variation }\end{array}$ & $\begin{array}{c}S_{\mathbf{a}} \\
{[\mathrm{\mu m}]}\end{array}$ & $\begin{array}{c}S_{\mathbf{d q}} \\
{[-]}\end{array}$ \\
\hline 1 & 178 & 11.1 & 68 & 73 & $+6.7 \%$ & 2.63 & 0.483 \\
2 & 173 & 7.8 & 51 & 54 & $+6.3 \%$ & 2.49 & 0.510 \\
3 & 173 & 7.8 & 51 & 54 & $+6.3 \%$ & 2.73 & 0.511 \\
4 & 176 & 6.0 & 42 & 47 & $+15.7 \%$ & 2.37 & 0.495 \\
5 & 209 & 4.8 & 40 & 45 & $+12.1 \%$ & 3.52 & 0.424 \\
6 & 210 & 6.6 & 49 & 51 & $+5.5 \%$ & 11.23 & 3.077 \\
\hline
\end{tabular}

and melting temperatures. The results in Table 1 also show that there is a correlation between the temperature dependence of hardness and the hardness measured at $+23^{\circ} \mathrm{C}$, since the softer materials at this temperature (those used for soles 4 and 5) have a higher temperature dependence with respect to the stiffer ones.

\subsection{Surface analysis}

The surface areas for design 1 and design 2 measured with the contrast liquid (see Supplementary Figure 2(b)) were of $46.1 \mathrm{~mm}^{2}$ and $39.7 \mathrm{~mm}^{2}$ respectively. The surface textures of the soles evaluated with optical profilometer are reported in Figure 4. Soles 1-4 present a morphology of the surface 
Table 2: Dynamic coefficient of friction (COF) and corresponding standard deviation for the different sole tested on wet porcelain and glass at $+20^{\circ} \mathrm{C}$, and ice at $-10{ }^{\circ} \mathrm{C}$.

\begin{tabular}{ccccccc}
\hline \multirow{2}{*}{ Sole } & \multicolumn{2}{c}{ Porcelain $\left(+20^{\circ} \mathrm{C}\right)$} & \multicolumn{2}{c}{ Glass $\left(+20^{\circ} \mathrm{C}\right)$} & \multicolumn{2}{c}{ Ice $\left(-10^{\circ} \mathrm{C}\right)$} \\
& $\mathrm{COF}$ & St. Dev. & $\mathrm{COF}$ & St. Dev. & $\mathrm{COF}$ & St. Dev. \\
\hline 1 & 0.36 & 0.01 & 0.54 & 0.01 & 0.12 & 0.01 \\
2 & 0.45 & 0.01 & 0.58 & 0.02 & 0.13 & 0.01 \\
3 & 0.45 & 0.01 & 0.58 & 0.02 & 0.13 & 0.01 \\
4 & 0.70 & 0.04 & 0.71 & 0.01 & 0.15 & 0.01 \\
5 & 0.58 & 0.03 & 0.67 & 0.01 & 0.14 & 0.01 \\
6 & 0.49 & 0.01 & 0.54 & 0.01 & 0.12 & 0.01 \\
\hline
\end{tabular}

texture very similar to each other. In fact not only the value of the heights of the peaks and the depth of the valleys is almost coincident, but also the distributions of the peaks and of the empty spaces within the area analysed are comparable. The image relative to sole 6 corresponds to a post-wear situation, showing the effect of life cycle on the surface. In Table 1 profile parameters of interest $S_{\mathrm{a}}$ and $S_{\mathrm{dq}}$ are reported for all soles. The surface texture morphology of soles 5 and 6 is different from the one of soles 1-4. In fact the materials used for soles 5 and 6 (plastic manufacturer B) have higher $S_{\mathrm{a}}$ with respect to the soles made of the materials from the other plastic manufacturer (plastic manufacturer A). More parameters according to ISO 25178 are reported in the Supplementary Table 1.

\subsection{Dynamic coefficient of friction}

The results obtained from friction measurements show tangible differences among soles made of different materials (Table 2). A higher COF were observed on glass with respect to wet porcelain stoneware for all samples. The COF measured on ice at $-10^{\circ} \mathrm{C}$ is significantly lower compared to those measured at $+20^{\circ} \mathrm{C}$ on porcelain stoneware and glass. Furthermore sole 4 and sole 5 present the highest COF among the samples tested on all the surfaces. On ice the difference is less pronounced, as intuitively expected.

The measure of COF on porcelain stoneware shows that the surface hardness has an effect on friction since softer materials present higher friction on all the different surfaces. This is evident comparing materials of soles 1,2 and 4 (that have a similar chemical composition and melting temperature). Also the comparison of the material of sole 5 with that of sole 6 shows 


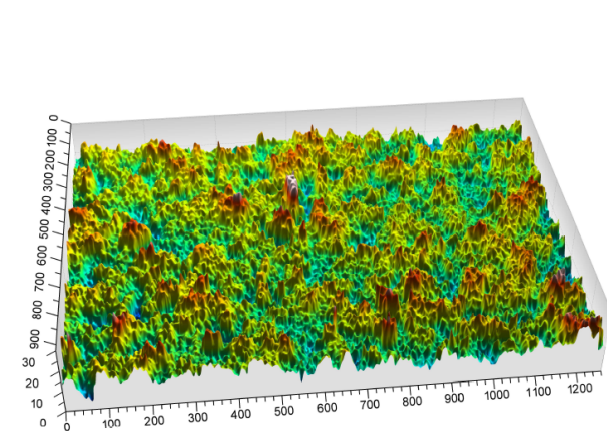

Sole 1
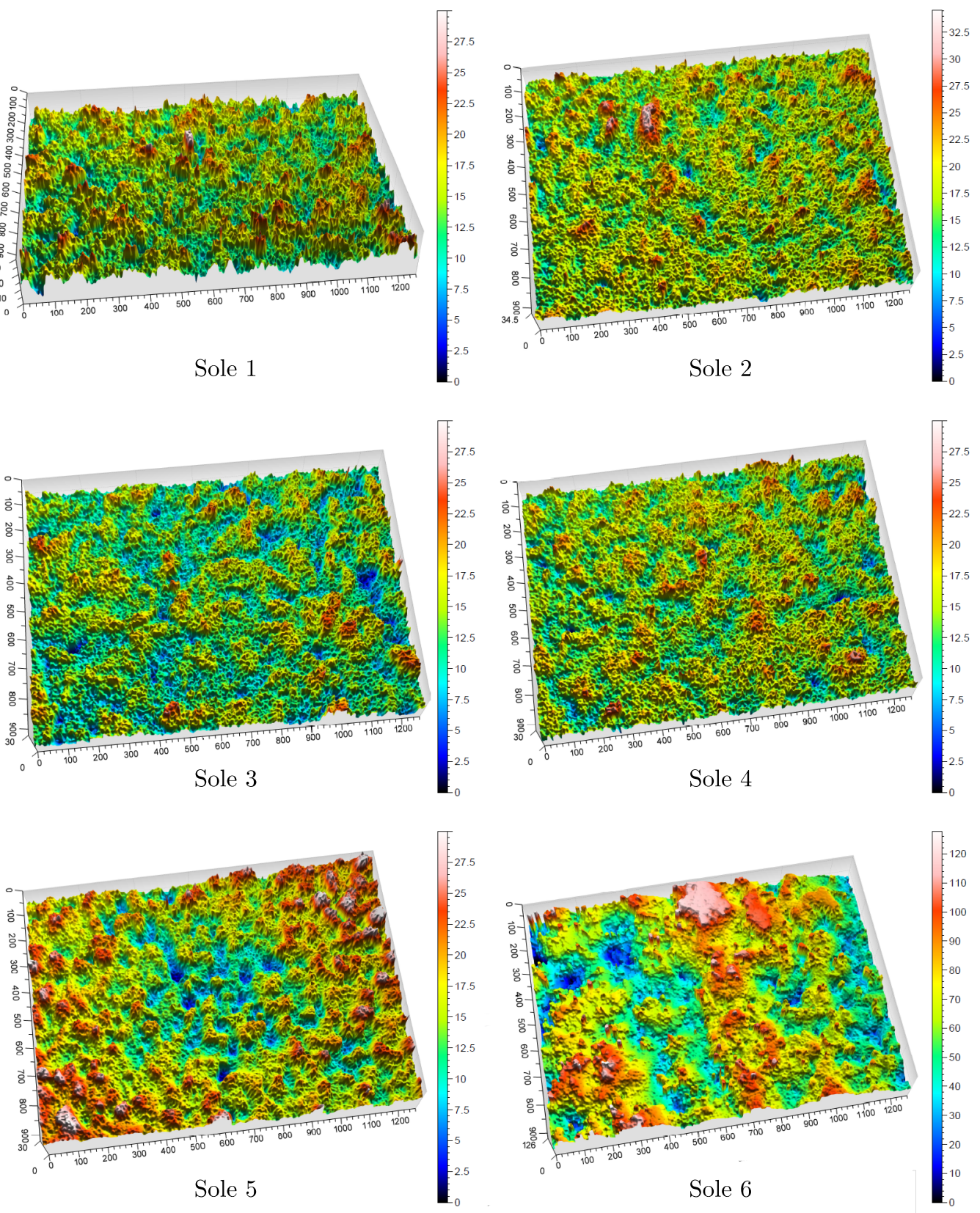

Figure 4: Profilometer 3D scans on the different soles tested. The colour bar and the axes are expressed in $\mu \mathrm{m}$. The image of sole 6 refers to the specimen after wear. 
the effect of hardness since the softer material of sole 5 has higher friction. The comparison of the materials made by different manufacturers (and with different crystalline structures) shows that the best material in terms of friction is the one used for sole 4 , which has a higher COF with respect to the material used for sole 5 that is softer (40 Shore D for sole 5 compared to 42 Shore $\mathrm{D}$ for sole 4 ). The difference can be related to the different crystalline structure (different melting temperature and lower crystallinity for sole 5) and to the different roughness of the surface $\left(S_{\mathrm{a}}\right.$ is higher for sole 5$)$. Similar trends were observed for the glass surface with a clear effect of surface hardness on friction. Nevertheless, in this case the difference between the COF of the harder and of the softer materials is smaller with respect to that observed on porcelain stoneware. The tests conducted on ice show small differences between the materials tested, since all the materials have very low friction on ice. This can be due to the lower temperature at which the tests were performed. At lower temperature the materials increases their stiffness but the increase is more consistent for the materials that are softer at $+23{ }^{\circ} \mathrm{C}$ (Table 1$)$. The comparison between friction and roughness indicates that materials with higher $S_{\mathrm{a}}$ (arithmetic mean height) have lower friction. Moreover, the higher COF of the material used for sole 4 with respect to the other materials can be ascribed to the greater number of contact points with the trampled surface. As can be seen from the comparison of binary images of areas acquired on soles 3 and 4 (Figure 5) and the relative diagram of the equivalent diameters of the grains identified, the surface of the sole 4 has a greater number of grains (probable contact point), which occupy a smaller area and have an equivalent diameter with better distribution.

\subsection{Ramp test}

The results of ramp tests (Table 3 ) show the same trend for the 3 testers, with sole 2 and sole 4 being those with more grip since the slip angle observed in those cases was higher. A clear effect of the design of the sole emerges. In particular, comparing soles 2 and 3 made of the same material (same hardness, crystallinity, and chemical composition) the design of sole 2 provides more grip compared to the design of sole 3 . Comparing the treads of sole 2 (design 1 in Figure 1(a)) with that of sole 3 (design 2 in Figure 1(b)) it is clear that the design used for sole 2 has more contact point with the surface compared to the design of sole 3 . This indicates that on porcelain tiles the grip behaviour is governed by the contact of the material with the floor surface. This is in

agreement with the results of the measure of the equivalent diameter. The 
(a)

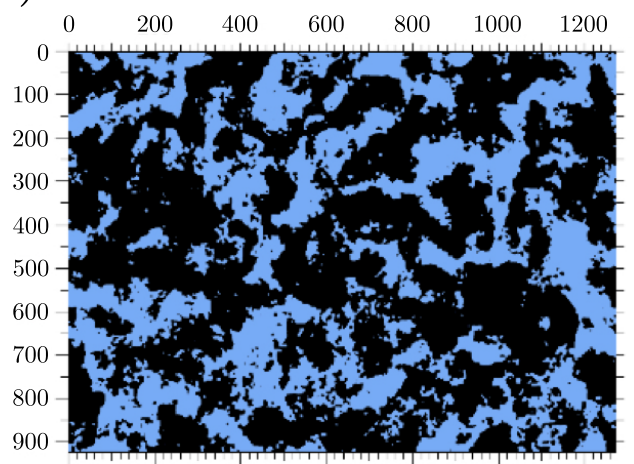

(b)

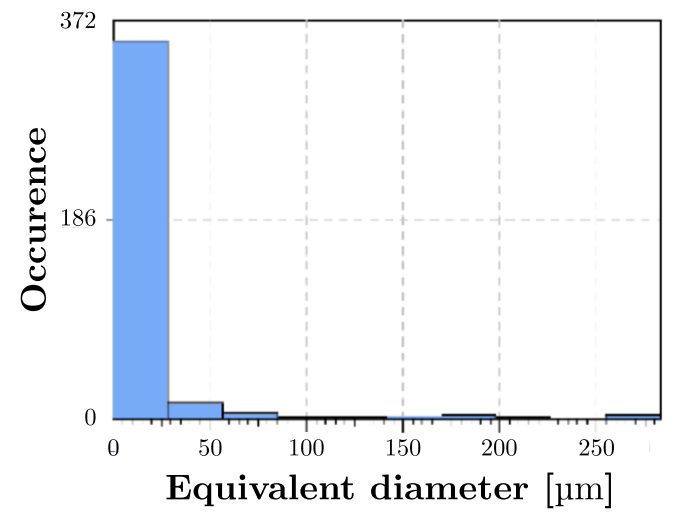

(c)

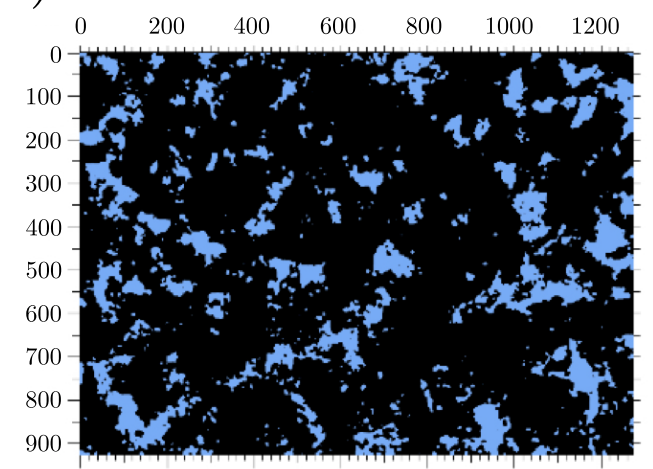

(d)

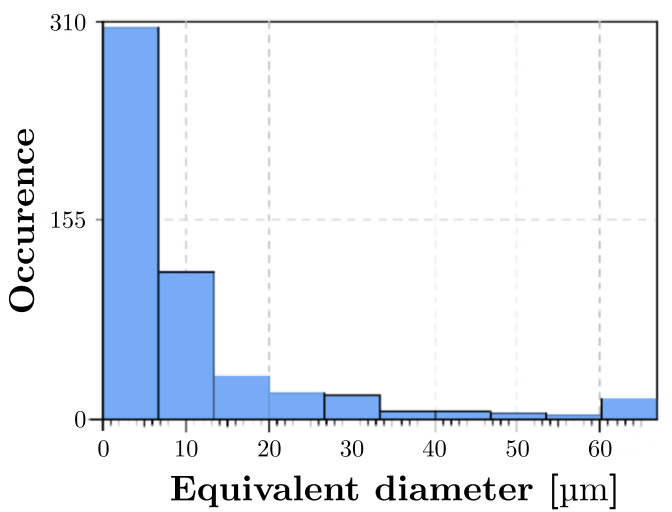

Figure 5: Binary images and diagrams of the equivalent diameter of an area of sole 3, (a) and (b), and sole 4, (c) and (d). 
Table 3: Results of the ramp tests on porcelain in wet condition, according to DIN 51130-R standard (DIN (2004)).

\begin{tabular}{cccccccc}
\hline \multirow{2}{*}{ Sole } & \multicolumn{2}{c}{ Tester 1 } & \multicolumn{2}{c}{ Tester 2 } & \multicolumn{2}{c}{ Tester 3 } & Average \\
& Slip [] & St. Dev. & Slip $\left[^{\circ}\right]$ & St. Dev. & Slip $\left[^{\circ}\right]$ & St. Dev. & Slip [ $\left.{ }^{\circ}\right]$ \\
\hline 1 & 13.0 & 0.3 & 13.7 & 0.4 & 13.2 & 0.4 & 13.3 \\
2 & 16.4 & 0.4 & 16.4 & 0.4 & 16.2 & 0.3 & 16.3 \\
3 & 14.5 & 0.1 & 14.9 & 0.1 & 14.9 & 0.2 & 14.8 \\
4 & 15.5 & 0.1 & 16.3 & 0.3 & 15.7 & 0.1 & 15.8 \\
5 & 13.8 & 0.2 & 14.6 & 0.3 & 14.0 & 0.4 & 14.1 \\
6 & 12.5 & 0.1 & 13.0 & 0.2 & 13.1 & 0.3 & 12.9 \\
\hline
\end{tabular}

comparison of the grip performance of soles with the same design and type of material shows a clear effect of material hardness on grip performances. In particular, softer materials have more grip compared to hard materials (comparing for example sole 1 with sole 2 or sole 5 with sole 6 ). This is in agreement with the measure of $\mathrm{COF}$ that indicates that soft materials have higher friction compared to hard materials. The COF measurement also let to explain the lower grip of sole 5 compared to sole 4 with similar hardness. Figure 6 depicts the slip angle vs. COF, showing the distinction between the two design types and the direct dependency of the slip angle to the friction coefficient.

\subsection{Finite element simulations}

From experiments a strong dependence of the friction coefficient to the sole material elasticity clearly emerges, and it is more evident on wet glass and porcelain. The experimental cases have been numerically reproduced and a summary of the parameters used is reported in Table 4 together with the COF resulting from simulations.

A series of finite element simulation with different elastic moduli and surface roughness was performed to extend the analysis domain, ranging the material stiffness from $25 \mathrm{MPa}$ to $200 \mathrm{MPa}(25,50,100,150,200 \mathrm{MPa})$ and mean roughness $S_{\mathrm{a}}$ from 1 to $12 \mu \mathrm{m}(1,2,4,6,12 \mu \mathrm{m}), S_{\mathrm{dq}}=0.28=$ const.). The results in form of $3 \mathrm{D}$ diagrams are shown in Figures $7(\mathrm{a})-(\mathrm{b})-(\mathrm{c})$ for the three different substrates tested (porcelain and glass at $+20^{\circ} \mathrm{C}$ and ice at $-10^{\circ} \mathrm{C}$, showing the dependence on both materials elasticity and surface roughness. Results confirms that in the analysed domain softer materials 


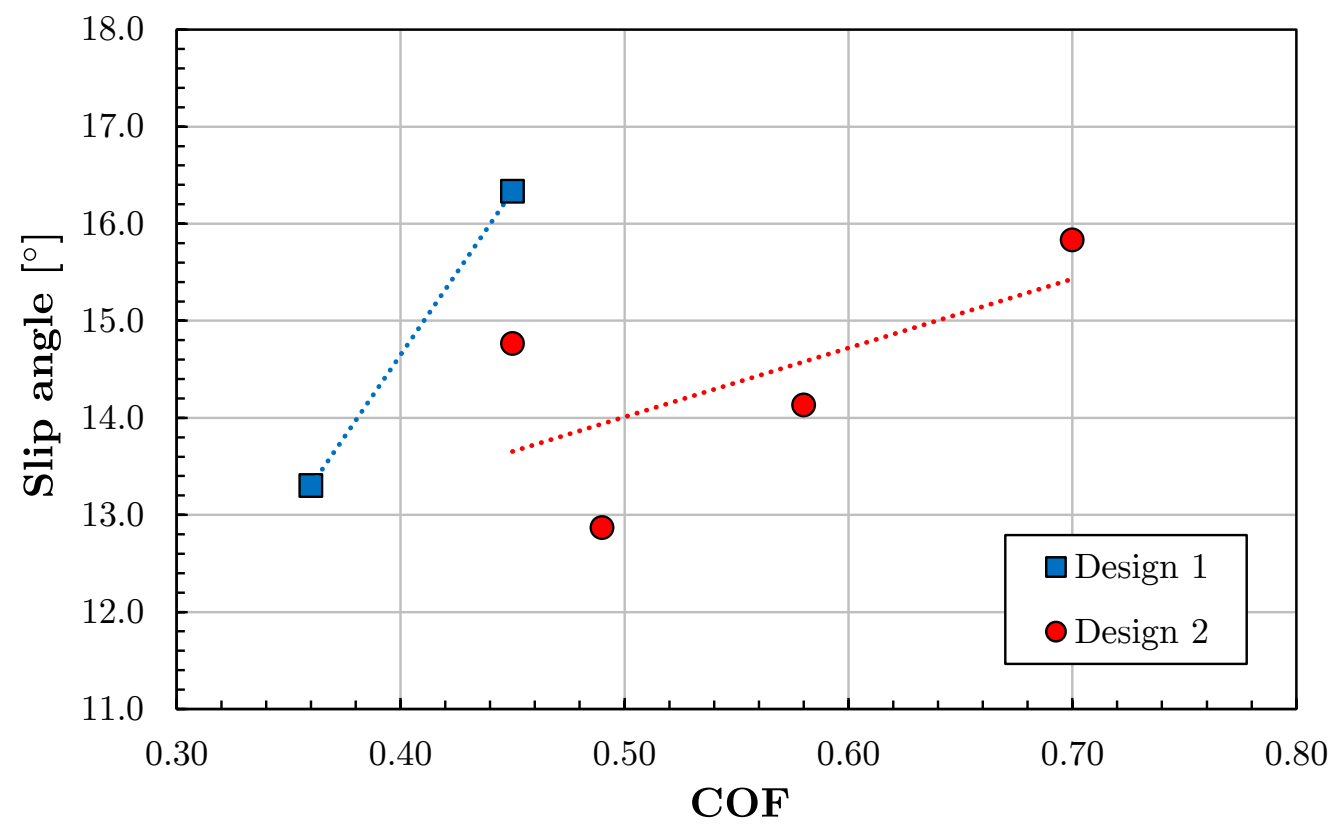

Figure 6: Slip angle from the ramp test on wet porcelain as a function of the COF. The plot show the direct dependence between the two quantities and the distinction of behaviour between the two group of soles with different design.

Table 4: Elastic material and surface roughness parameters used in the FEM model for the different soles according to material characterization and surface analysis and resulting COF from the simulations modelling the real experiments (Table 2).

\begin{tabular}{ccccccccc}
\hline Sole & $\begin{array}{c}E[\mathrm{MPa}] \\
+23^{\circ} \mathrm{C}\end{array}$ & $\begin{array}{c}E[\mathrm{MPa}] \\
-10^{\circ} \mathrm{C}\end{array}$ & $\nu$ & $\begin{array}{c}A \equiv S_{\mathbf{a}} \\
{[\mu \mathrm{m}]}\end{array}$ & $\begin{array}{c}\lambda \\
{\left[\mathrm{\mu m}^{-1}\right]}\end{array}$ & $\begin{array}{c}\text { Porc. } \\
\text { Glass }\end{array}$ & Ice \\
\hline 1 & 136 & 178 & 0.48 & 2.63 & 0.259 & 0.36 & 0.52 & 0.12 \\
2 & 54 & 64 & 0.48 & 2.49 & 0.290 & 0.47 & 0.56 & 0.13 \\
3 & 54 & 64 & 0.48 & 2.73 & 0.265 & 0.46 & 0.57 & 0.13 \\
4 & 33 & 44 & 0.48 & 2.37 & 0.296 & 0.72 & 0.72 & 0.16 \\
5 & 30 & 39 & 0.48 & 3.52 & 0.170 & 0.58 & 0.68 & 0.15 \\
6 & 49 & 54 & 0.48 & 11.23 & 0.387 & 0.48 & 0.54 & 0.13 \\
\hline
\end{tabular}


and low sole roughness should be preferred for enhancing grip for the specific environmental condition (wet surfaces and ice), corroborating experimental observations. Experimental points are depicted on the surfaces generated from FEM simulations. Figure 7(e) shows the experimental points of all tested soles together with a selection of simulation output that refers to $S_{\mathrm{a}}=2.0$, thus the trace of the three surfaces is there depicted. Similarly, Figure 7(f) shows the experimental point together with simulation points at a reference Young's modulus $E=50 \mathrm{MPa}$. The estimated valued of $\mu_{\infty}$ to be set in the contact are $0.49,0.32$, and 0.11 for wet porcelain, wet glass, and ice respectively at the corresponding testing temperatures. $\mu_{0}$, namely the local static friction coefficients, were set for all cases as 2 times the corresponding dynamic value, but since at the sliding regime is $v / v_{\text {crit }} \gg 1$ we verified that $\mu_{0}$ does not influence the global COF measured in simulations. The simulation derived COFs (Table 4)and the experimentally observations (Table 2) are in good agreement.

\section{Discussion and conclusions}

The carried analysis on the friction behaviour of ski boot soles for alpine skiing shows that the dynamic coefficient of friction depends on the roughness and on the crystalline structure of the materials, with the smother surfaces and the softer materials having the best grip properties. The thermoplastic polyurethane soles have more grip on glass compared to porcelain stoneware surfaces. The grip on ice is significantly lower than wet surfaces, also due to the low temperature that increases the polyurethane stiffness. Therefore, materials that limit their hardness increase at low temperature should be preferred.

It is well known (Takahashi et al. (1996)) that the length of copolymers blocks and molecular weight in polyurethane can have a significant effect on the thermal and mechanical properties of the materials. In particular, the copolymers block composition determines the crystalline structure that is responsible for the overall thermo-mechanical characteristics of the material and consequently, as demonstrated by the carried experiments, also for the frictional properties of surfaces. We have also demonstrated the role of surface roughness at the micrometric scale, that is a parameter generally neglected in the design of this kind of product. Its role is as important as the material mechanical stiffness. Thus, also the wear behaviour must be properly taken 

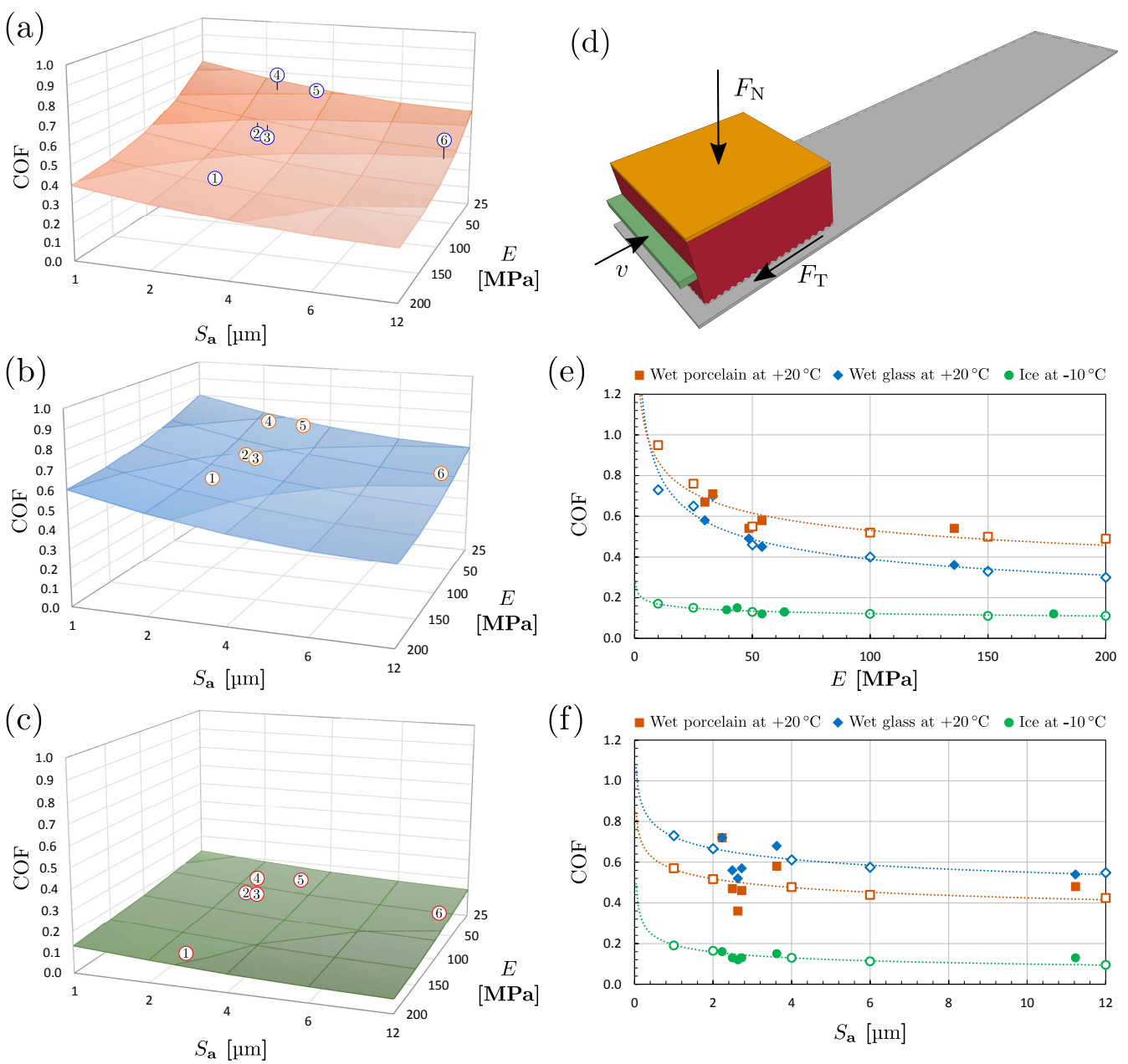

Figure 7: COF as a function of material elasticity (Young's Modulus $E$ ) and surface roughness $\left(S_{\mathrm{a}}\right)$ from FEM numerical simulations for (a) wet porcelain at $+20^{\circ} \mathrm{C}$, (b) wet glass at $+20^{\circ} \mathrm{C}$, (c) ice at $-10^{\circ} \mathrm{C}$. Surfaces are generated from FEM simulations, while dots represents the measure from friction experiments on the 6 soles. (d) Image of the FEM simulation setup showing the deformable slider on a rigid flat substrate. (e) COF vs. sole material Young's Modulus for the three tested substrates. Filled dots are experimental tests while the empty dots are results of FEM simulation for an average roughness $S_{\text {a }}$ $=2.0$, fitted with the power law $\mathrm{COF} \propto E^{k_{1}}$, with $k_{1}$ estimated to be equal to -0.325 , $-0.215,-0.144$ for wet porcelain, wet glass and ice respectively in the tested environmental conditions. (f) COF vs. sole average roughness. Empty dots are results of FEM simulations for $E=50 \mathrm{MPa}$ fitted with a power law $\mathrm{COF} \propto E^{k_{2}}$, with $k_{2}$ estimated to be equal to $-0.124,-0.119$, and -0.290 respectively for the three surfaces. 
into account, since the progressive flattening of the surface may let the sole to deviate from its designed grip properties.

Finite element numerical simulations corroborate the experimentally observed dependence of the COF. The design of experiments made with FEM simulations let to enlarge the analysis domain -and in a controllable wayto quantify the role of sole surface geometrical and mechanical properties. The actual dependence of the COF to the two factors, hardness/stiffness and surface roughness, was evaluated by two-way ANOVA analysis. Being the critical Fisher-test variable $F_{\text {crit,[0.95] }}=3.0069$, the values of $F$ for the three test surface (porcelain, glass and ice respectively) are 40.8954, 16.7756, 9.4978 for the first factor (elastic modulus/hardness) and 5.5683, 16.4013, 26.4845 for the second factor (surface average roughness). Thus for all cases is $F \geq F_{\text {crit, [0.95] }}(p \leq 0.05)$, confirming that the tuning of the surface morphology and material stiffness are both viable ways to tailor frictional properties of soles.

The experimental measures of grip on inclined wet surfaces show the importance also of the macroscopic patterning design of the sole surface. The ANOVA made on the slippery angle with respect to the friction coefficient (slippery test made on wet porcelain) states the correlation between the slip angle and the $\operatorname{COF}\left(F=60.3361 \geq F_{\text {crit },[0.95]}=3.8379, p \leq 0.05\right)$. Thus, net of the sole design, the COF can be used as target parameter for the choice of the sole material. The comparison of two soles with different designs indicates that the higher friction is associated to the wider actual contact area with the ground, whose role is clearly distinguishable in the slippery test (Figure 6). The same interpretation can explain the role of surface roughness and material compliance at the lower scale level Figure 5.

This numerical test/design approach is, to the best of authors knowledge, still unemployed in this sector, and represents a valid tool for the design and prediction of frictional surfaces for ski boots and other footwear. For example engineered composites and/or graded materials could be virtually designed and tested in relation the competing requirements of grip with the ground and energy transfer from the skier to the to the ski. Anisotropic frictional properties could be also designed. In the end, the results remark the importance of both micro and macro-surface patterning and of material design as well, giving guidelines in the engineering of ski boot soles with tailored frictional properties. 


\section{Acknowledgements}

NMP is supported by the European Research Council (ERC PoC 2015 SILKENE no. 693670) and by the European Commission H2020 under the Graphene FET Flagship Core 1 (WP14 "Polymer Composites", no. 696656) and under the FET Proactive ("Neurofibres" no. 732344). SS acknowledges support from SILKENE.

\section{Conflict of Interest}

The authors declare that the research was conducted in the absence of any commercial or financial relationships that could be construed as a potential conflict of interest.

\section{Copyright}

This is the post-print version of the following article M. Moncalero, S. Signetti, B. Mazzanti, P. Bruzzi, N.M. Pugno, M. Colonna. Effect of material elastic properties and surface roughness on grip performances of ski boot soles under wet and icy conditions. International Journal of Industrial Ergonomics. 61:62-70, 2017 which is available in its original version at http://dx.doi.org/10.1016/j.ergon. 2017.04 .004$.

\section{References}

(2003). ISO 868. Plastics and ebonite - Determination of indentation hardness by means of a durometer (Shore hardness).

(2004). DIN 51130. Antislip Classifications.

(2005). ISO 5355. Alpine ski-boots - Requirements and test methods.

(2008). ISO 9523. Touring ski-boots for adults - Interface with touring ski-bindings - Requirements and test methods.

(2012). ISO 25178. Geometrical product specifications (GPS) - Surface texture: Areal.

Budinski, K. G. (1997). Resistance to particle abrasion of selected plastics. Wear, 203-204, 302-309. doi:10.1016/S0043-1648(96) 07346-2. 
Colonna, M., Nicotra, M., \& Moncalero, M. (2013). Materials, Designs and Standards Used in Ski-Boots for Alpine Skiing. Sports, 1, 78-113. doi:10.3390/sports1040078.

Colonna, M., Nicotra, M., \& Moncalero, M. (2014). Ski Boots for Alpine Skiing: Designs, Materials and Testing Procedures. Lambert Academic Publishing.

Corazza, S., \& Cobelli, C. (2005). An innovative ski-boot: design, numerical simulation and testing. Journal of Sports Science and Medicine, 4, 229-238. URL: http://www . jssm. org/research . php?id=jssm-04-229.xml.

Derler, S., Kausch, F., \& Huber, R. (2008). Analysis of factors influencing the friction coefficients of shoe sole materials. Safety Science, 46, 822-832. doi:10.1016/j.ssci.2007.01.010.

Fleischer, N. L., Melstrom, P., Yard, E., Brubaker, M., \& Thomas, T. (2014). The epidemiology of falling-through-the-ice in alaska, 1990-2010. Journal of Public Health, 36, 235-242. doi:10.1093/pubmed/fdt081.

Gao, C., Abeysekera, J., Hirvonen, M., \& Aschan, C. (2003). The effect of footwear sole abrasion on the coefficient of friction on melting and hard ice. International Journal of Industrial Ergonomics, 31, 323-330. doi:10.1016/S0169-8141(02)00234-2.

Grönqvist, R., \& Hirvonen, M. (1995). Slipperiness of footwear and mechanisms of walking friction on icy surfaces. International Journal of Industrial Ergonomics, 16, 191-200. doi:10.1016/0169-8141(94)00095-K.

Heinrich, G., \& Klüppel, M. (2008). Rubber friction, tread deformation and tire traction. Wear, 265, 1052-1060. doi:10.1016/j. wear.2008.02.016.

Li, K. W., Wu, H. H., \& Lin, Y.-C. (2006). The effect of shoe sole tread groove depth on the friction coefficient with different tread groove widths, floors and contaminants. Applied Ergonomics, 37, 743-748. doi:10.1016/ j. apergo.2005.11.007.

Natali, A. N., Fontanella, C. G., Carniel, E. L., Venturato, C., Pavan, P. G., \& Todros, S. (2014). Evaluation of the mechanical behaviour of Telemark ski boots: Part II - structural analysis. Journal of Sports Engineering and Technology, 228, 204-212. doi:10.1177/1754337114525139. 
Nicotra, M., Moncalero, M., \& Colonna, M. (2015). Effect of the viscoelastic properties of thermoplastic polymers on the flexural and rebound behaviours of ski boots. Journal of Sport Engineering and Technology, 299, 199-210. doi:10.1177/1754337114564481.

Otsuki, M., \& Matsukawa, H. (2013). Systematic Breakdown of Amontons' Law of Friction for an Elastic Object Locally Obeying Amontons' Law. Scientific Reports, 3, 1-6. doi:10.1038/srep01586.

Parisotto, D., Marcolin, G., Marcolin, R., \& Pellizzer, M. (2012). Investigation of the mechanical performances of material and structural configuration of telemark ski boots. Footwear Science, 4, 51-57. doi:10.1080/19424280. 2011.639096.

Qi, H. J., \& Boyce, M. C. (2005). Stress-strain behavior of thermoplastic polyurethanes. Rubber Chemistry and Technology, 37, 817-839. doi:10. 1016/j.mechmat. 2004.08.001.

Qi, H. J., Joyce, K., \& Boyce, M. C. (2003). Durometer hardness and the stress-strain behavior of elastomeric materials. Rubber Chemistry and Technology, 76, 419-435. doi:10.5254/1.3547752.

Takahashi, T., Hayashi, N., \& Hayashi, S. (1996). Structure and properties of shape-memory polyurethane block copolymers. Journal of Applied Polymer Science, 60, 1061-1069. doi:10.1002/(SICI) 1097-4628(19960516)60: 7<1061: :AID-APP18>3.0.CO;2-3.

Tsai, Y.-J., \& Powers, C. M. (2013). The influence of footwear sole hardness on slip characteristics and slip-induced falls in young adults. Journal of Forensic Sciences, 58, 46-50. doi:10.1111/j.1556-4029.2012.02296.x. 